Original Research Article

\title{
Evaluation of inappropriate prescribing to the hospitalized elderly patients in Al Shifa hospital, Gaza, Palestine
}

\author{
Lina K. Massoud*, Hala Z. Al Agha, Mahmoud H. Taleb
}

Department of Pharmacology, Faculty of Pharmacy, Al-Azhar University, Gaza, Palestine

Received: 11 September 2016 Accepted: 12 October 2016

\section{*Correspondence to:}

Dr. Lina K. Massoud, Email: massoudlina2009@ hotmail.com

Copyright: (C) the author(s), publisher and licensee Medip Academy. This is an openaccess article distributed under the terms of the Creative Commons Attribution NonCommercial License, which permits unrestricted noncommercial use, distribution, and reproduction in any medium, provided the original work is properly cited.

\begin{abstract}
Background: The current study aimed to assess the prevalence of inappropriate prescribing (IP) for hospitalized elderly patients at Al Shifa Hospital, Gaza, Palestine.

Methods: This study was a retrospective cross-sectional study. A total of 2385 prescribed drugs for 380 elderly inpatients in internal, cardiology, and respiratory departments were screened for IP. Four criteria were used to detect IP using chart review method; Drug-drug interactions (DDIs), drug contraindications (CI), duplication of therapy and Beers' criteria 2012.

Results: The results showed that $44.2 \%$ of patients had at least one IP. Around $33.2 \%$ of the patients had DDIs, $19.2 \%$ had IP according to Beers' criteria and $1.1 \%$ had drug CI. There was no duplication of therapy. A total of 323 IP instances were detected. Of them, $74 \%$ for DDIs and $24.8 \%$ for Beers' criteria. The prevalence of overall IP was significantly influenced by age ( $p$ value $=0.024)$, polypharmacy $(\mathrm{p}$-value $<0.001)$, degree of morbidity ( $\mathrm{p}$ value $<0.001$ ), and departments ( $\mathrm{p}$-value $=0.018$ ). The prevalence of DDIs was influenced by polypharmacy ( $\mathrm{p}$-value $<0.001)$, degree of morbidity ( $\mathrm{p}$ value $=0.001$ ), and departments $(p-v a l u e=0.005)$. Finally, the prevalence of IP according to Beers' criteria was significantly influenced by departments with the highest in the cardiology department (29.7\%) (P-value $=0.007)$.

Conclusions: Although the overall IP was common, it was not far higher than that reported worldwide. The majority of IP was DDIs. Age, polypharmacy, degree of morbidity and departments influenced the occurrence of IP.
\end{abstract}

Keywords: Beers' criteria, Contraindications, Drug-drug interactions, Elderly, Hospital, Inappropriate prescribing

\section{INTRODUCTION}

Inappropriate prescribing (IP) is a single term that covers three concepts; under prescribing, overprescribing, and misprescribing. ${ }^{1,2}$ Overprescribing relates to the practice of prescribing more medications than what are clinically required. ${ }^{3}$ Under prescribing refers to the failure of prescribing drugs that are needed, ${ }^{1}$ while misprescribing refers to incorrectly prescribing a drug that is needed in term of choice of medication, drug interactions, dose, duration of therapy, duplication and follow up. ${ }^{2}$ Inappropriate prescribing (IP) is particularly relevant for the elderly (65 yrs or older), as they have the highest susceptibility to the effects of drugs. They experience age-related physiological changes, which often influence the pharmacokinetic and pharmacodynamic status of drugs. ${ }^{4}$ Moreover, the elderly often have several concurrent illnesses that need several medications, thereby, increasing the risk of adverse drug events, drugdrug and drug-disease interactions. ${ }^{5}$

A number of studies have investigated IP in the elderly. Different criteria have been used to identify IP; the most frequently cited one is Beers' criteria. The criteria are a list of potentially inappropriate medications (PIMs) that should be avoided in elderly, developed in 1991 for nursing homes and expanded and revised several times to include all setting of geriatric care. ${ }^{6}$ The final updated criteria in 2012 are divided into three categories: PIMs and classes to avoid in older adults, PIMs and classes to avoid in older adults with certain diseases and syndromes that the drugs listed can exacerbate, and finally medications to be used with caution in older adults. ${ }^{6}$ Data from those studies have shown a high prevalence of IP in 
elderly, ranges from $2.2 \%$ to $35.6 \%$ in community dwelling patients, ${ }^{7,8,9}$ and from $10.5 \%$ to $54.7 \%$ in nursing home patients. ${ }^{5,10,11}$ In addition, IP in hospitals is also prevalent. The prevalence of IP was $36.2 \%$ among elderly inpatients in a medical center in Taiwan. ${ }^{12}$ In a study in the U.S. involving 384 hospitals, the prevalence of IP was $49 \%$ among elderly inpatients. ${ }^{13}$

Hospitalization has been associated with a higher incidence of adverse outcomes including functional decline, delirium, and falls in the elderly. ${ }^{14}$ This can be explained by the fact that elderly inpatients may be exposed to new and possibly unnecessary medications, multiple providers and restrictive hospital formularies that require reconciliation with home medications. ${ }^{15}$

No information is available regarding IP affecting Palestinian inpatients. Limited data from one study suggested that polypharmacy is common among chronic elderly patients. ${ }^{16}$ Furthermore, no study was conducted to thoroughly investigate IP using comprehensive criteria for the detection of IP, whether in the primary care or in the hospital settings. Therefore; in depth investigation of IP in hospitalized elderly patients in Gaza was needed.

The current study assessed the prevalence of IP in elderly inpatients. The criteria used for detecting IP were the updated Beers' criteria 2012, DDIs, drug CI, and duplicate therapy. It also examined the different variables that might be associated with an increased risk of IP. These variables include hospital departments, gender, age, polypharmacy and number of diseases at admission.

\section{METHODS}

\section{Study design and setting}

This study is a cross-sectional retrospective study. It was conducted at Al Shifa Hospital, Gaza, Palestine. Medical files for elderly patients admitted to the hospital over two months (From $1^{\text {st }}$ November 2012 to $31^{\text {st }}$ December 2012) were screened for IP. Three departments were investigated, internal medicine department, cardiology department, and respiratory department.

\section{Sample size and selection criteria}

All the elderly inpatients $\geq 65$ years old who were admitted to the three assigned departments during the study period at Al Shifa Hospital were included in the study. Three hundred eighty elderly inpatients (177 men and 203 women) were assessed for different types of IP. Twenty five patients who had unclear files and those whose their files did not include any information about the prescribed drugs were excluded from the study. Regarding drugs prescribed, 2385 drug orders were screened for IP. All the prescribed drug categories were included without any exclusion. Only drugs administered on regular basis were recorded. Drugs applied on-demand basis and drugs used once only were not included.

\section{Data collection and assessment criteria}

Chart review method was used for monitoring IP. Data sheet was designed for each patient and was numbered by the researcher. This sheet included all information about the patient: sex, age, patient physical data (weight, blood pressure), patient laboratory data, allergy to drug, past medical history, diagnosis, regular drugs (drug trade name, strength, drug generic name, directions, duration and date), analysis [appropriate, inappropriate] and reasons for inappropriateness. The drugs were classified according to the British National Formulary 2012. The criteria used to assess IP in this study were Beers' criteria 2012, DDIs, drug CI (include drug-disease interactions and allergy to drugs) and duplicate therapy. Clinical data were used beside prescription data to assess IP. Data for monitoring IP were taken from four references. ${ }^{6,17-19}$ All potential DDIs were determined and classified according to severity; significant DDIs refer to the interactions that likely require monitoring by the doctor, serious DDIs refer to the interactions that require regular monitoring by the doctor or alternate medications may be needed, and contraindicated DDIs refer to the combination of drugs that should never be used because of high risk for dangerous interactions. ${ }^{17}$

\section{Data analysis}

The prevalence of IP was calculated by dividing the number of patients with at least one IP by the total number of patients multiplied by 100 . This method was used to calculate the prevalence rates of overall IP, IP according to Beers' criteria, DDIs, and drug CI (drugdisease interactions). Excel software and statistical package for social science version 15.0 (SPSS) program were used to analyse data. Numerical data were summarized using means and standard deviations. Categorical data were summarized as frequencies and percentages. All P-values were obtained from two tests (T-test and Chi-square test).

T-test was used to compare mean age between men and women, mean number of diseases between men and women, and mean number of prescribed drugs per patient between men and women. Chi-square test was used to study the differences between men and women in the different departments, in the different degrees of morbidity, in patients on polypharmacy and those not and in the percentages of patients in each category of drugs prescribed. It also was used to compare the prevalence of IP among different age groups, in patients prescribed $<5$ drugs to patients prescribe 5 or more drugs, among patients with different degrees of morbidity, among different departments, and in men to that in women. The results were considered to be statistically significant if $\mathrm{P}$ values $\leq 0.05$. 


\section{RESULTS}

\section{Principle characteristics of the study population}

A total of 380 elderly inpatients' medical files were screened for IP. Women composed $53.4 \%$ while men composed $46.6 \%$ of the study sample. Patients' age was categorized into three groups; (65-69 yrs), (70-79 yrs) and (80 and over yrs). Patients of the age interval 70-79 yrs constituted the largest proportion $44.7 \%$. There were no statistically significant differences between men and women regarding their characteristics. Detailed characteristics of the patients are shown in Table 1. The total number of drugs prescribed was 2385. Internal department had the highest number of prescribed drugs $1062(44.5 \%)$, and the most frequent prescribed drugs were cardiovascular drugs 1129 (47.3\%).

Table 1: Principle characteristics of the patients.

\begin{tabular}{|c|c|c|c|c|}
\hline Characteristics & Total $(n=380)$ & Men $(n=177)$ & Women $(n=203)$ & P-value $^{\mathrm{a}}$ \\
\hline Mean age in years $\pm(\mathrm{SD})$ & $72.9 \pm 6.6$ & $73 \pm 6.7$ & $72.8 \pm 6.4$ & $0.727^{b}$ \\
\hline $\begin{array}{l}\text { Department: } \mathbf{n}(\boldsymbol{\%})^{\mathbf{d}} \\
\text { Cardiology } \\
\text { Respiratory } \\
\text { Internal }\end{array}$ & $\begin{array}{c}101(26.6) \\
88(23.1) \\
191(50.3) \\
\end{array}$ & $\begin{array}{l}53(29.9) \\
38(21.5) \\
86(48.6)\end{array}$ & $\begin{array}{l}48(23.7) \\
50(24.6) \\
105(51.7)\end{array}$ & $0.367^{\mathrm{c}}$ \\
\hline $\begin{array}{l}\text { Diseases } \\
\text { Mean } \pm(\mathrm{SD})\end{array}$ & $2.8 \pm 1.3$ & $2.7 \pm 1.3$ & $2.9 \pm 1.3$ & $0.125^{\mathrm{b}}$ \\
\hline $\begin{array}{l}\text { Patients' having } \mathbf{n}(\boldsymbol{\%})^{\mathbf{d}} \\
1 \text { disease } \\
2 \text { diseases } \\
\geq 3 \text { diseases }\end{array}$ & $\begin{array}{l}61(16.1) \\
94(24.7) \\
225(59.2)\end{array}$ & $\begin{array}{l}36(20.3) \\
41(23.2) \\
100(56.5)\end{array}$ & $\begin{array}{l}25(12.3) \\
53(26.1) \\
125(61.6)\end{array}$ & $0.104^{\mathrm{c}}$ \\
\hline $\begin{array}{l}\text { Prescribed drugs } \\
\text { Mean } \pm(\mathrm{SD})\end{array}$ & $6.3 \pm 2.5$ & $6.03 \pm 2.5$ & $6.49 \pm 2.5$ & $0.073^{\mathrm{b}}$ \\
\hline $\begin{array}{l}\text { Patients prescribed } \mathbf{n}(\%)^{\mathbf{d}} \\
\geq 5 \text { drugs (polypharmacy) } \\
<5 \text { drugs }\end{array}$ & $\begin{array}{l}291(76.6) \\
89(23.4)\end{array}$ & $\begin{array}{c}130(73.5) \\
47(26.6)\end{array}$ & $\begin{array}{l}161(79.3) \\
42(20.7)\end{array}$ & $0.178^{\mathrm{c}}$ \\
\hline $\begin{array}{l}\text { Drug categories }{ }^{\mathbf{e}} \mathbf{n}(\boldsymbol{\%})^{\mathbf{d}} \\
\text { Gastrointestinal drugs } \\
\text { Respiratory drugs } \\
\text { Cardiovascular drugs } \\
\text { Central nervous system drugs } \\
\text { Endocrine drugs } \\
\text { Infection drugs } \\
\text { Nutrition and blood drugs } \\
\text { Musculoskeletal and joint diseases } \\
\text { Miscellaneous drugs }\end{array}$ & $\begin{array}{l}242(63.7) \\
100(26.3) \\
303(79.7) \\
66(17.4) \\
186(49) \\
227(59.7) \\
39(10.3) \\
15(4) \\
21(5.5)\end{array}$ & $\begin{array}{l}113(63.8) \\
47(26.6) \\
135(76.3) \\
33(18.6) \\
78(44.1) \\
100(56.5) \\
22(12.4) \\
10(5.7) \\
10(5.7)\end{array}$ & $\begin{array}{l}129(63.6) \\
53(26.1) \\
168(82.8) \\
33(16.3) \\
108(53.2) \\
127(62.6) \\
17(8.4) \\
5(2.5) \\
11(5.4)\end{array}$ & $\begin{array}{l}0.952^{c} \\
0.922^{c} \\
0.117^{c} \\
0.540^{c} \\
0.076^{c} \\
0.229^{c} \\
0.194^{c}\end{array}$ \\
\hline
\end{tabular}

$\mathrm{n}=$ number of patients; ${ }^{\mathrm{a}} \mathrm{P}$-values $\leq 0.05$ were considered significant. ${ }^{\mathrm{b}} \mathrm{T}$-test, ${ }^{\mathrm{c}}$ Qui-square; ${ }^{\mathrm{d}} \mathrm{n}(\%)$ percentages are given within parenthesis with the total number of patients as the denominator; ${ }^{\mathrm{e}}$ Classification of drugs was done according to BNF (2012),; ${ }^{\mathrm{f}}$ Miscellaneous drugs include urinary tract, malignant diseases and immunosuppressant, oropharynx and skin drugs.

\section{Inappropriate prescribing}

One hundred and sixty eight patients $(44.2 \%)$ were subjected to at least one IP in this study. Table 2 presents the overall prevalence of IP, and the prevalence rates of DDIs, Beers 'criteria drugs and CI (drug-disease interactions) in the entire sample. No case was registered neither regarding allergy to drugs nor duplication of therapy.

A total of 323 IP instances were detected. Drug-drug interactions (DDIs) constituted the majority $74 \%$, followed by IP according to Beers' criteria (24.8\%). Only 4 IP $(1.2 \%)$ were related to CI (drug-disease interactions). Some patients had more than one type of IP.

The total instances of DDIs were 239 involving 49 different drugs and 98 different pairs of DDIs. Digoxin and ciprofloxacin were the most frequent drugs associated with DDIs. Glucocorticosteroids, atorvastatin and heparin were frequently associated with DDIs as well. Significant DDIs constituted the majority (68.2\%) of the detected DDIs, followed by serious DDIs (31\%), while only $2(0.8 \%)$ instances were contraindicated. 
Aminophylline was the most frequent drug involved in serious DDIs (Table 3). Digoxin, however, was the most frequent drug involved in significant DDIs (Table 4).

Some examples of serious DDIs were the use of ciprofloxacin with aminophylline and omeprazole with clopidogrel. Regarding significant DDIs, hydrocortisone was ordered with ciprofloxacin and atorvastatin with digoxin. Only one contra-indicated DDI was identified which was using ceftriaxone I.V. with calcium gluconate injection.

Table 2: The prevalence of IP in elderly inpatients.

\begin{tabular}{|lc|}
\hline \multicolumn{2}{|l|}{ The percentage of at least one patient with IP } \\
$\begin{array}{l}\text { Total number of patients experienced at } \\
\text { least one IP } \mathrm{n}(\%)^{\mathrm{a}}\end{array}$ & $168(44.2 \%)$ \\
\hline $\begin{array}{l}\text { Number of patients experienced at least } \\
1 \text { DDI n (\%) }\end{array}$ & $126(33.2 \%)$ \\
\hline $\begin{array}{l}\text { Number of patients experienced at least } \\
1 \text { IP according to Beers' criteria } \mathrm{n}(\%)^{\mathrm{a}}\end{array}$ & $73(19.2 \%)$ \\
\hline $\begin{array}{l}\text { Number of patients experienced at least } \\
1 \mathrm{CI}\left(\text { Drug-disease interactions) } \mathrm{n}(\%)^{\mathrm{a}}\right.\end{array}$ & $4(1.1 \%)$ \\
\hline
\end{tabular}

$\mathrm{n}=$ number of patients; ${ }^{\mathrm{a}}(\%)$ Percentages are given within parenthesis with the total number of patients (380) as the denominator.

The study identified a total of 80 instances of IP according to Beers' criteria (69 instances independent of diagnosis and 11 instances must be used with caution in elderly patients). Metoclopramide was the most frequent Beers' criteria drug prescribed (Figure 1). No instance was registered regarding PIMs considering diagnosis.

Table 3: The most common prescribed drugs involved in serious ${ }^{\text {a }}$ DDIs.

\begin{tabular}{|ll|}
\hline Drug & $\begin{array}{l}\text { Drug interaction instances } \\
\text { involving the specified } \\
\text { drug } \mathbf{n}(\%)^{\mathbf{b}}\end{array}$ \\
\hline Aminophylline & $17(23 \%)$ \\
\hline Ciprofloxacin & $15(20.3 \%)$ \\
\hline Clarithromycin & $15(20.3 \%)$ \\
\hline Digoxin & $11(14.9 \%)$ \\
\hline Glucocorticosteroid & $9(12.2 \%)$ \\
\hline Ceftriaxone & $8(10.8 \%)$ \\
\hline Heparin & $8(10.8 \%)$ \\
\hline Warfarin & $8(10.8 \%)$ \\
\hline Enoxaparin & $7(9.5 \%)$ \\
\hline Omeprazole & $7(9.5 \%)$ \\
\hline Azithromycin & $6(8.1 \%)$ \\
\hline Carbamazepine & $6(8.1 \%)$ \\
\hline
\end{tabular}

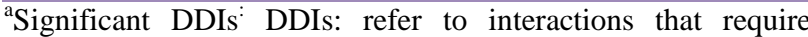
regular monitoring by the doctor or alternate medications may be needed ${ }^{17} ;{ }^{b} n=$ number of DDIs involving the specified drug. Percentages are given within parenthesis with the total number of instances of serious DDIs as a denominator (74).
Table 4: The most common prescribed drugs involved in significant ${ }^{\mathrm{a}}$ DDIs.

\begin{tabular}{|ll|}
\hline Drug & $\begin{array}{l}\text { Drug interaction instances } \\
\text { involving the specified } \\
\text { drug } \mathbf{n}(\%)^{\mathbf{b}}\end{array}$ \\
\hline Digoxin & $32(19.6 \%)$ \\
\hline Atorvastatin & $30(18.4 \%)$ \\
\hline Glucocorticosteroids & $28(17.2 \%)$ \\
\hline Ciprofloxacin & $26(16 \%)$ \\
\hline Heparin & $25(15.3 \%)$ \\
\hline Spironolactone & $19(11.7 \%)$ \\
\hline Aspirin & $16(9.8 \%)$ \\
\hline Enalapril & $14(8.6 \%)$ \\
\hline Furosemide & $13(8 \%)$ \\
\hline Omeprazole & $12(7.4 \%)$ \\
\hline Calcium carbonate & $11(6.8 \%)$ \\
\hline
\end{tabular}

${ }^{a}$ Serious DDIs: refer to interactions that require regular monitoring by the doctor or alternate medications may be needed ${ }^{17} ;{ }^{b} \mathrm{n}=$ number of DDIs involving the specified drug. (\%) percentages are given within parenthesis with the total number of instances of significant DDIs as a denominator (163).

Some examples of CI (drug-disease interactions) which found in the present study were the use of spironolactone in severe renal impairment, and metformin in congestive heart failure. ${ }^{17}$

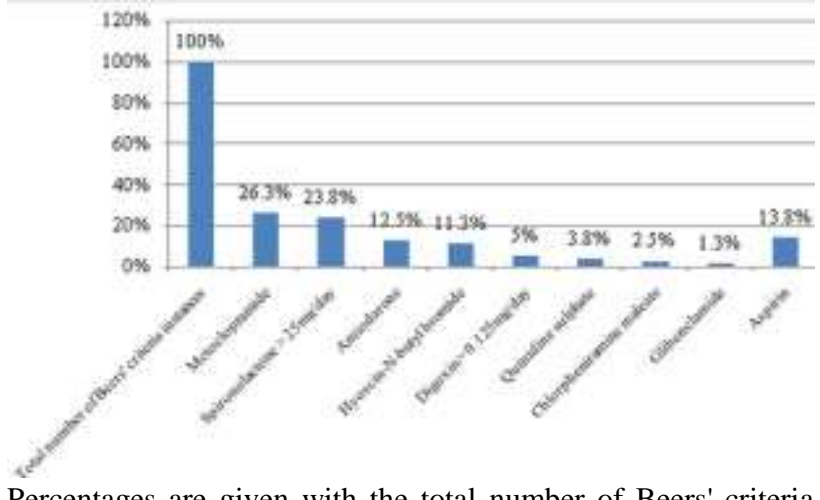

Percentages are given with the total number of Beers' criteria instances as a denominator (80).

Figure 1: The instances of potential IP identified by Beers' criteria.

Regarding the variables associated with the detected IP, the prevalence of overall IP was significantly influenced by age with the highest in those aged $80+$ yrs $(54.9 \%)$ $(\mathrm{P}$-value $=0.024)$, polypharmacy $(\mathrm{P}$-value $<0.001)$, degree of morbidity based on the number of diseases at admission with the highest in those having 3 or more diseases $(52.9 \%)$ (P-value $<0.001)$, and departments with the highest in the respiratory department $(53.4 \%)(\mathrm{P}-$ value $=0.018)$. While the prevalence of DDIs was significantly influenced by polypharmacy (pvalue $<0.001)$, degree of morbidity with the highest in those having 3 or more diseases (40.4\%) (Pvalue $=0.001)$, and departments with the highest in the respiratory department $(44.3 \%)(\mathrm{P}-\mathrm{value}=0.005)$. Finally, 
the prevalence of IP according to Beers' criteria was significantly influenced by departments with the highest in the cardiology department $(29.7 \%)(\mathrm{P}$-value $=0.007)$.

\section{DISCUSSION}

\section{Inappropriate Prescribing}

About $44.2 \%$ of patients were subjected to at least one IP in this study. This result indicates that IP was common and significant at the time of the study among the hospitalized elderly patients at Al Shifa Hospital. We expect that the variations in healthcare providers training and experiences, medication knowledge deficiency and the absence of pharmacist's involvement in patients care might have contributed to the high prevalence of IP in the present study.

The result of the present study was higher than what was found by Liu et al. study $(36.2 \%){ }^{12}$ This difference may be due to the use of Screening Tool of Older People Potential inappropriate prescriptions (STOPP) criteria in Liu et al. study. The STOPP criteria assess DDIs, drug disease interactions, drugs that adversely affect older patients at risk of falls and duplicate drug class prescriptions. It lists only 65 instances of potentially IP, while the present study detected all the possible IP according to the predefined criteria.

Yet, the result of the present study was lower than what was found by Hanlon et al. ${ }^{20}$ They reported that $91.9 \%$ of hospitalized frail elderly patients had IP. This may be due to the use of Medication Appropriateness Index (MAI) which assesses ten elements of prescribing: indication, effectiveness, dose, correct direction, practical direction, DDIs, drug-disease interactions, duplication, duration and cost. However, the present study did not assess indication, effectiveness, dose, direction, duration and cost. In addition, frail elderly inpatients often have poor health and thus they may require regular prescribed drug therapy. In Hanlon et al. ${ }^{20}$ study, the patients used both prescription and non-prescription drugs. All these reasons lead to higher IP among these patients. Our study involved both frail and fit elderly inpatients.

The result by Steinman et al. ${ }^{3}$ was nearly similar to that in the present study (42\%). They assessed IP in 196 elderly outpatients taking 5 or more drugs. A combination of the Beers criteria 2003, the MAI and the assessment of underutilization of medications instrument were used. Although the sample size was smaller, the wider criteria used permitted detecting more types of IP. In addition, the patients taking 5 or more drugs are more susceptible to IP.

The prevalence of DDIs in the present study was relatively high $33.2 \%$, but it was lower than that reported by other studies conducted among hospitalized elderly patients. $^{21,22}$ This may be explained by several methodological aspects, as well as specific aspects of the setting or the study itself. Most studies which used computerized detection programs found that potential DDIs are common. ${ }^{21,22}$ However, these databases are not geriatric-specific, and, more importantly, they overestimate the true clinical significance. In fact, clinically significant DDIs are much less frequent. ${ }^{20}$ It is therefore necessary to increase the validity of DDIs criteria by focusing on drug interactions with sufficient clinical significance. In the present study, this was done by considering clinical information of the patient and by using three references for the detection of DDIs. ${ }^{17-19}$ This permitted a more accurate analysis, and resulted in a lower prevalence of DDIs.

The most common example of serious DDIs in our study was the concomitant use of aminophylline I.V. and ciprofloxacin. This can decrease aminophylline clearance and increase plasma levels and symptoms of toxicity. Ciprofloxacin inhibits the hepatic enzyme CYP1A2 and hepatic/intestinal enzyme CYP3A4 metabolism. Serious and fatal reactions have included cardiac arrest, seizure, status epilepticus, and respiratory failure. ${ }^{17}$ If concomitant use cannot be avoided, aminophylline level must be monitored and dosage must be adjusted as needed. ${ }^{17}$ Cefuroxime and levofloxacine are safe alternatives which can be used with aminophylline. ${ }^{23}$ In the present study, monitoring of aminophylline level in blood was not available in the hospital.

Another common example of serious DDIs was ordering omeprazole with clopidogrel. Omeprazole decreases the effect of clopidogrel by inhibiting the hepatic enzyme CYP2C19 metabolism, and thus decreasing the formation of the active antiplatelet metabolite. ${ }^{1724}$ Pantoprazole ${ }^{25}$ and famotidine ${ }^{26}$ can be alternatives to omeprazole to be used with clopidogrel.

Regarding significant DDIs, hydrocortisone was used with ciprofloxacin. Coadministration of quinolone antibiotics and corticosteroids may increase risk of tendon rupture. ${ }^{17}$

Another example of significant DDIs was using digoxin with atorvastatin. Digoxin is known to undergo intestinal secretion mediated by P-glycoprotein. Atorvastatin increases the level or effect of digoxin by inhibiting pglycoprotein (MDR1) efflux transporter. This interaction must be monitored closely. ${ }^{17}$ But in the current study digoxin levels were not monitored.

Concerning CI drug combinations, ceftriaxone I.V. was ordered with calcium gluconate injection. In this combination there is a risk of potentially fatal particulate precipitation in lungs and kidneys. For patients $>28$ days, calcium should be given in sequence after ceftriaxone once infusion line has been flushed, but not simultaneously in the same bag or line (chemically incompatible). ${ }^{17}$ In our study the information about administration was insufficient. 
The prevalence of IP according to Beers' criteria (19.2\%) was lower than that reported by Rothberg et al. (49\%) and Momin et al. (40\%) in hospitalized elderly patients. ${ }^{13,27}$ As Rothberg et al. who used Beers' criteria 2003 had larger and more representative sample size. ${ }^{13}$ While Momin et al. who used Beers' criteria 2012, had higher number of drugs prescribed per patient $($ mean $=9.52 \pm 2.75) .{ }^{27}$ The criteria used whether Beers' criteria 2003 or the updated one in 2012 also affected the results. Some drugs like daily fluoxetine, ferrous sulfate $>$ $325 \mathrm{mg} /$ day and propoxyphene have been omitted in the 2012 updated Beers criteria. Others like glyburide, metoclopramide and spironolactone have been added to the Beers' criteria $2012 .{ }^{6}$ Few drugs to be prescribed with caution in the elderly have also been added as a new category in the revised Beers' criteria. ${ }^{27}$

In the current study, the most prevalent IP according to Beers' criteria independent of diagnosis was metoclopramide. Metoclopramide can cause extrapyramidal effects including tardive dyskinesia. ${ }^{6}$ The use of low dose aspirin for the primary prevention of cardiac events was also prevalent among elderly aged $\geq$ 80 years old. It was listed in Beers' criteria as PIM to be used in caution in elderly $\geq 80$ years old for the prevention of cardiac events. There is a lack of evidence of benefit versus risk in such patients. ${ }^{6}$

The prevalence of drug-disease interactions in the current study was very low $1.1 \%$, and do not go with the prevalence rates found in other studies. ${ }^{7,28}$ Lindblad et al. recorded a $40 \%$ prevalence of drug-disease interactions among frail elderly inpatients. ${ }^{28}$ These patients often have multiple diseases and take many drugs and this can increase drug-disease interactions among them.

In the present study, spiranolactone was ordered for a patient who had severe renal impairment (serum creatinine was $3.1 \mathrm{mg} / \mathrm{dl}$ ). In this case spironolactone is contraindicated and must be avoided due to risk of hyperkalemia. $^{17,29}$

Metformin was ordered to a patient with congestive heart failure (CHF). Patients with $\mathrm{CHF}$ have an increased risk for lactic acidosis; the risk for lactic acidosis increases with the patient's age. ${ }^{17}$

In the present study no patient had results concerning allergy to drugs. This may be explained by lacking of checking for allergy by the doctors, inadequate knowledge about drug allergy and unreported information from the patients about drug allergy. In contrast to other studies, no duplication of therapy was found in the present study. ${ }^{7,30}$

\section{Variables associated with IP}

In the present study, age, polypharmacy, degree of morbidity and departments influenced the occurrence of IP. Gender, however, did not affect IP. Cahir et al. found that, the overall IP was influenced by old age, gender and polypharmacy. ${ }^{30}$ The prevalence of DDIs was influenced by polypharmacy, degree of morbidity and departments. Rahmawati et al. found that, the number of potential DDIs in elderly inpatients tends to increase with increasing the number of medications used per day. ${ }^{21}$ In the present study, the lowest prevalence of overall IP and DDIs was in the internal department. This may indicate that internists provided higher-quality inpatient care, while the highest was in the respiratory department due to lack of monitoring aminophylline levels in blood in the respiratory department.

Finally, The prevalence of IP according to Beers' criteria was highest in cardiology department, as many Beers' criteria drugs have cardiologic applications. For example, spironolactone, amiodarone, digoxin, and quinidine sulphate. In addition, this may be explained by lacking cardiologists' knowledge regarding Beers' criteria drugs and their consequences in the elderly.

An important limitation of this study was the deficiency of some data due to poor documentation and file keeping in the hospital. In addition, the consequences of IP were not addressed. Furthermore, other IP conditions were not investigated namely indication, effectiveness, dose, directions, drug-food interactions, duration, underuse of effective agents and cost. Finally, this study was done only in three departments at Al Shifa hospital, and was restricted to one hospital in the Gaza Strip; therefore the results cannot be generalizable to all elderly inpatients in Palestine.

\section{CONCLUSION}

In conclusion, the present study suggested that the overall IP was common among hospitalized elderly patients at Al Shifa hospital in Gaza-Palestine, but it was not far higher than that reported worldwide. The majority of IP was related to potential DDIs. Beers' criteria drugs were also prevalent and they were frequently prescribed by the doctors at Al Shifa hospital. No case was registered neither regarding allergy to neither drugs nor duplication of therapy. The prevalence of overall IP in the current study was influenced by age, polypharmacy, morbidity and departments, whereas, the prevalence of DDIs was influenced by polypharmacy, morbidity and departments. It was observed that internists provided higher-quality inpatient care. Lack of the monitoring of aminophylline levels in blood in the respiratory department increased the overall IP and DDIs. Departments also affected the occurrence of IP according to Beers' criteria and it was the highest in cardiology department.

\section{RECOMMENDATIONS}

We recommend that the findings of this study should be incorporated in an educational material at the hospital level to orient the physicians to good prescribing. In addition, physicians should avoid prescribing 
inappropriate drugs and should use alternatives for them. Furthermore, health administration at Al Shifa hospital must provide laboratory monitoring for aminophylline levels in blood. The ministry of health must put a plan to introduce computerized decision support systems in hospitals to provide support for decision-making in patient care. Moreover, a clinical pharmacy service must be established at Al Shifa hospital. A comprehensive geriatric evaluation and management care approach must be considered to reduce IP. Finally, similar studies should be carried out at other Palestinian hospitals in all Palestinian regions. The results of these studies must be spread to the relevant sectors in order to improve prescribing quality and reduce the cost of such prescribing.

\section{ACKNOWLEDGEMENT}

We would like to thank, Al Azhar University, Ministry of Health, and the working staffs in the general directorate for human research and in the Archives of Al Shifa Hospital for their help and support.

Funding: No funding sources

Conflict of interest: None declared

Ethical approval: The study was approved by the Institutional Ethics Committee of Faculty of Pharmacy, Al-Azhar University and by the director of general directorate for human research in the Ministry of Health

\section{REFERENCES}

1. Simonson W, Feinberg JL. Medication-related problems in the elderly: Defining the issues and identifying solutions. Drug Aging. 2005;22:559-69.

2. Spinewine A, Schmader KE, Barber N, Hughes C, Lapane KL, Swine C, et al. Appropriate prescribing in elderly people: How well can it be measured and optimised? Lancet. 2007;370(9582):173-84.

3. Steinman MA, Landefeld CS, Rosenthal GE, Berthenthal D, Sens S, Kaboli PJ. Polypharmacy and prescribing quality in older people. J Am Geriatr Soc. 2006;54(10):1516-23.

4. Turnheim K. When drug therapy gets old: Pharmacokinetics and pharmacodynamics in the elderly. Exp Gerontol. 2003;38:843-53.

5. Gallagher P, Barry $\mathrm{P}, \mathrm{O}^{\prime}$ Mahony $\mathrm{D}$. Inappropriate prescribing in the elderly. $\mathrm{J}$ Clin Pharm Ther. 2007;32(2):113-21.

6. American Geriatric Society. American Geriatric Society updated Beers' criteria for potentially inappropriate medication use in older adults. J Am Geriatr Soc. 2012;60:616-31.

7. Saab YB, Hachem A, Sinno S, El-Moalem H. Inappropriate medication use in elderly Lebanese outpatients, prevalence and risk factors. Drug Aging. 2006;23(9):743-75.

8. Simon SR, Chan KA, Soumerai SB, Wagner AK, Andrade SE, Feldstein AC, et al. Potentially inappropriate medication use by elderly persons in
U.S. Health Maintenance Organizations, 2000-2001. J Am Geriatr Soc. 2005;53(2):227-32.

9. Vlahović-Palcevski V, Bergman U. Quality of prescribing for the elderly in Croatia-computerized pharmacy data can be used to screen for potentially inappropriate prescribing. Eur J Clin Pharmacol. 2004;60(3):217-20.

10. Ruggiero C, Lattanzio F, Aquila GD, Gasperini B, Cherubini A. Inappropriate drug prescriptions among older nursing home residents. Drugs Aging. 2009;26(suppl. 1):15-30.

11. Rancourt C, Moisan J, Baillargeon L, Verreault R, Laurin D, Gregoire JP. Potentially inappropriate prescriptions for older patients in long-term care. BMC Geriatr. 2004;15(4):1-9.

12. Liu CL, Peng LN, Chen YT, Lin MH, Liu LK, Chen LK. Potentially inappropriate prescribing for elderly medical inpatients in Taiwan: A hospital based study. Arch. Gerontol. Geriatr. 2012;55(1):148-51.

13. Rothberg MB, Pekow PS, Liu F, KorcGrodzicki B, Brennan MJ, Bellantonio S, et al. Potentially inappropriate medication use in hospitalized elders. J Hosp Med. 2008;3(2):91-102.

14. Friedman SM, Mendelson DA, Bingham KW, Mc Cann RM. Hazards of hospitalization: Residence prior to admission predicts outcomes. Gerontologist. 2008;48(4):537-41.

15. Coleman EA, Smith JD, Raha D, Min SJ. Post hospital medication discrepancies: Prevalence and contributing factors. Arch Intern Med. 2005;165(16):1842-7.

16. Taleb MH, Abed A, Dahoudi A, Najim A, Ahmed A. Polypharmacy in Primary Care Practices among Chronic Elderly Patients in Gaza Strip. Pharmacology \& Pharmacy. 2014;5:291-7.

17. American Society of Health System Pharmacists. AHFS drug information, 2009. Available at http://www.medscape.com/pharmacists. Accessed August, 2012.

18. Royal Pharmaceutical Society. British National Formulary 63. London: Pharmaceutical Press; 2012.

19. Stockley IH. Stockley's Drug Interactions. 7th ed. London: The Pharmaceutical Press; 2005.

20. Hanlon JT, Artz MB, Pieper CF, Lindblad CI, Sloane $\mathrm{RJ}$, Ruby CM, et al. Inappropriate medication use among frail elderly inpatients. Ann Pharmacother. 2004;38(1):9-14.

21. Rahmawati F, Hidayyati N, Rochman W, Sulaiman S. Potentially of drug-drug interactions in hospitalized geriatric patients in a private hospital, Yogyakdarta, Indonesia. Asian Journal of Pharmaceutical and Clinical Research. 2010;3(3):191-4.

22. Rosas-Carrasco O, García-Peña C, Sánchez-García S, Vargas-Alarcón G, Gutiérrez-Robledo LM, JuárezCedillo T. The relationship between potential drugdrug interactions and mortality rate of elderly hospitalized patients. Rev Invest Clin. 2011;63(6):564-73. 
23. Antoniou T, Gomes T, Mamdani MM, Juurlink DN. Ciprofloxacin-induced theophylline toxicity: A population-based study. Eur J Clin Pharmacol. 2011;67(5):521-6.

24. Allen MJ, Mclean-Versey P. Interaction between clopidogrel and proton pump inhibitors. CMAJ. 2009;180(12):1228-9.

25. Lin SL, Chang HM, Liu CP, Chou LP, Chan JW. Clinical evidence of interaction between clopidogrel and proton pump inhibitors. World $\mathbf{J}$ Cardiol. 2011;3(5):153-64.

26. Taha AS, McCloskey C, Prasad R, Bezlyak V. Famotidine for the prevention of peptic ulcers and oesophagitis in patients taking low-dose aspirin (FAMOUS): a phase III, randomised, double-blind, placebo-controlled trial. Lancet. 2009;374:119-25.
27. Momin TG, Pandya RN, Rana DA, Patel VJ. Use of potentially inappropriate medications in hospitalized elderly at a teaching hospital: A comparison between Beers 2003 and 2012 criteria. Indian J Pharmacol. 2013;45(6):603-7.

28. Lindblad CI, Artz MB, Pieper CF, Sloane RJ, Hajjar ER, Ruby CM, et al. Potential drug-disease interactions in frail, hospitalized elderly veterans. Ann Pharmacother. 2005;39(3):412-7.

29. Chua D, Lo A, Lo C. Spironolactone use in heart failure patients with end-stage renal disease on hemodialysis: Is it safe? Clin Cardiol. 2010;33(10),604-8.

30. Cahir C, Faheg T, Teeling M, Teljeur C, Feeling J, Bennett K. Potentially inappropriate prescribing and cost outcomes for older people: A national population study. Br J Clin Pharmacol. 2010;69(5):543-52.

Cite this article as: Massoud LK, Al Agha HZ, Taleb MH. Evaluation of inappropriate prescribing to the hospitalized elderly patients in Al Shifa hospital, Gaza, Palestine. Int J Basic Clin Pharmacol 2016;5:2376-83. 